Terr. Atmos. Ocean. Sci., Vol. 18, No. 3, 415-436, August 2007

\title{
Modeling Water Vapor in the Upper Troposphere and Lower Stratosphere
}

\author{
Line Gulstad $^{1, *}$ and Ivar S. A. Isaksen ${ }^{1}$
}

(Manuscript received 16 June 2005, in final form 8 February 2006)

\begin{abstract}
Upper troposphere and lower stratosphere (UTLS) water vapor is investigated using a general circulation model, the Community Atmosphere Model 3.0 (CAM3.0). Seasonal variability in UTLS water vapor, temperature and zonal wind, based on model simulation results for the period 1991 2000, are analyzed. Results are validated against satellite data from the Halogen Occultation Experiment (HALOE) and ERA-40 reanalyzes from ECMWF. The model captures the seasonal cycle in temperature as well as water vapor. The zonal wind deviates from the reanalysis data in the tropics as the model is not able to reproduce the Quasi-Biennial Oscillation (QBO). Outside the tropics, the zonal wind corresponds very well with the ERA-40 zonal wind. The model is able to reproduce the seasonal signal in the tropical stratospheric water vapor; i.e., the Tape Recorder Signal. This indicates a realistic Brewer-Dobson circulation in the model. However, the Tape Recorder signal attenuates too fast compared to the HALOE data, suggesting a too strong horizontal mixing between the tropical stratosphere and mid latitudes. CAM3.0 shows considerable improvements in UTLS temperatures as well as water vapor compared to earlier generations of the NCAR general circulation models.
\end{abstract}

(Key words: Water vapor, GCM modeling, Upper troposphere, Lower stratosphere, Seasonal)

\footnotetext{
${ }^{1}$ Department of Geosciences, Section of Meteorology and Oceanography, University of Oslo, Oslo, Norway

* Corresponding author address: Dr. Line Gulstad, Department of Geosciences, Section of Meteorology and Oceanography, University of Oslo, Oslo, Norway; E-mail: linegul@geo.uio.no doi: 10.3319/TAO.2007.18.3.415(EA)
} 


\section{INTRODUCTION}

Water vapor is a key tracer in the upper troposphere and lower stratosphere (UTLS) region. From a radiative point of view water vapor is the most dominant greenhouse gas and as such involved in important climate feedback loops. From a chemical point of view water vapor is the source of the hydroxyl radical and important for ozone chemistry. Stratospheric water vapor and its changes influence the formation of polar stratospheric clouds (PSCs), which initiates ozone depletion in the Antarctic and Arctic winter stratosphere. In the lower stratosphere water vapor is a nearly conserved quantity and thus a valuable tracer for transport studies. Tropopause temperatures and water vapor vary significantly with season. Due to very weak horizontal mixing in the tropical lower stratosphere the seasonal signal in water vapor is preserved following the upward and poleward propagation of the Brewer-Dobson circulation (Brewer 1949). This seasonal signal is often cited as the "Tape Recorder Signal" (Mote et al. 1996), and provides valuable information of the general circulation of the stratosphere. The tape recorder signal is suitable for transport analyzes in observational data (Clark et al. 2001; Randel et al. 2001), and for transport validation of general circulation models, GCMs. The quasi biennal oscillation (QBO) as well as the El Niño/Southern Oscillation (ENSO) are important factors for the interannual variability of stratospheric water vapor. Reproducing lower stratospheric water vapor distribution and its variability have been a challenge in GCM studies. Many GCMs have problems with cold biases at the tropical tropopause and in polar regions. Since the tropical tropopause temperature is one of the important factors controlling the amount of water vapor that enters the stratosphere, these cold biases influence stratospheric water vapor significantly. This in turn affects the heating rates in the models. Heating rates affect transport which again is very important for stratospheric water vapor. A too fast BrewerDobson circulation is a long term problem in GCMs. Although the development of sophisticated transport schemes together with better resolution in the models are reducing this problem. Continuous work to improve the models' ability to reproduce the stratosphere to troposphere exchange and realistic stratospheric circulation are needed.

Stratospheric water vapor is also affected through methane oxidation since water vapor is a product when methane is oxidized by the hydroxyl radical. An increase in methane concentrations at the surface will lead to increased conversion of stratospheric methane to stratospheric water vapor. Methane increases are documented through observations (IPCC 2001).

ENSO is well resolved in the models since many models force the climate with observed sea surface temperatures. On the other hand the Quasi Biennal Oscillation (QBO) represents a challenge in many GCMs. Only a few models are able to produce an internal QBO signal, the general state of the art is to assimilate QBO or not represent QBO at all in the models.

When discussing water vapor in the atmosphere a number of factors must be taken into account due to water vapor being a key component in describing the climate system. This paper is focusing on the upper troposphere and lower stratosphere, including some stratospheric tropospheric exchange (STE) processes. In the upper troposphere water vapor is mainly controlled by the local hydrological cycle. Processes involving evaporation, condensation and precipitation are determining a water vapor field with large spatial and temporal variability yielding a water vapor lifetime of hours to days. The tropopause region is characterized by extreme gradients in temperature as well as water vapor. Moving from the upper troposphere 
to the lower stratosphere we find a completely different regime. The stable and stratified stratosphere inhibits the typical fast vertical mixing that we find in the troposphere. This results in an extremely dry stratosphere with water vapor lifetimes of months to years. While the amount of water entering the stratosphere through the tropical tropopause region is strongly controlled by the very cold tropical tropopause temperatures, the water vapor in the stratosphere is controlled by dynamics and chemistry on which water vapor itself has a significant influence. Polar stratospheric clouds or tropical subvisible cirrus clouds are important sinks for lower stratospheric water vapor; however, these processes are limited in time and located to certain regions of the lower stratosphere.

This paper presents a validation of the general circulation model Community Atmosphere Model (CAM3.0) with respect to lower stratospheric water vapor. CAM3.0 is the latest version of the NCAR general circulation model and is based upon the previous versions CCM2 and CCM3. Controlling factors for water vapor like temperature, zonal wind and stratospheric transport are validated against observational data and reanalyses.

\section{PROCESSES GOVERNING UTLS WATER VAPOR}

\subsection{Lower Stratospheric Water Vapor and Dynamics}

The meridional circulation of the stratosphere known as the Brewer-Dobson Circulation (Brewer 1949; Dobson 1956) consists of three parts: rising motion in the tropics, poleward transport in the stratosphere and sinking motion at the poles. The air is lifted out of the tropical upper troposphere where it experiences a minimum in water vapor concentrations as it passes through the very cold tropical tropopause. The mechanisms behind the Brewer-Dobson Circulation are complex. A first guess on the driving mechanism would be a thermal latitudinal gradient as for the tropospheric Hadley circulation. However, this is only a minor component of the general stratospheric circulation. As the air moves poleward from the Equator there is an increase in zonal velocity to conserve angular momentum. However, this velocity is not as high as we might expect from an angular momentum conservation point of view. In the absence of any considerable friction in the stratosphere this can only be caused by wave breaking. Rossby waves that originate from the troposphere caused by topography, meridional temperature gradients and the Coriolis deflection create planetary waves that propagate vertically into the stratosphere. Reaching the stratosphere the wave breaks depositing its easterly momentum and slowing down the westerly wintertime polar jet. The Brewer-Dobson circulation is a winter time phenomenon. It is almost none existent in the summer hemisphere where the mass flux is small and downward. Due to hemispheric differences the wave activity in the Northern hemisphere is much stronger than in the Southern hemisphere. This influences the strength of the Brewer-Dobson circulation resulting in a larger mass flux transported by the general circulation in the stratosphere during Northern Hemisphere winter (Holton et al. 1995; Rosenlof 1995; Rosenlof et al. 1997). This interhemispheric asymmetry is very important for the lower stratospheric water vapor field.

The QBO (Baldwin et al. 2001) is known as an oscillation of the east-west zonal wind in the tropical stratosphere. The QBO signal descends through the middle and lower stratosphere 
at a rate of approximately $1 \mathrm{~km}^{\text {month }}{ }^{-1}$. This oscillation is not directly tied to the annual cycle, but has an approximate period of 28 months. The stratospheric temperatures are affected by the QBO through the thermal wind equation. These thermal anomalies induce a modification to the normal Brewer-Dobson circulation. Depending on the QBO phase, the circulation will be either speeded up or weakened. This has significant impact on the stratospheric distribution of $\mathrm{H}_{2} \mathrm{O}_{\text {mix }}$ and other tracers in the lower stratosphere, since QBO is essential for the upward transport of source gases like water vapor, methane, nitrous oxide and CFCs in the tropical stratosphere. Additionally QBO induces large changes in meridional gradients in the subtropics (O’Sullivan and Dunkerton 1997).

Other smaller scale dynamical features important for the stratospheric tropospheric exchange are phenomena like blocking anticyclones, cut off low pressure systems and tropopause folds connected with synoptic scale weather systems (Holton et al. 1995).

The El Niño/Southern Oscillation (ENSO) is regarded as a free oscillation of the oceanatmosphere system and is associated with warm (El Niño) and cold (La Niña) sea surface temperatures in the eastern equatorial Pacific. This is closely connected to the Walker Circulation (Walker 1924), which describes large east west shifts of mass between the Indian and west Pacific oceans and the east Pacific Ocean. El Niño events are largely correlated with enhanced water vapor values in the mid troposphere (Jackson et al. 1996; Scaife et al. 2003; Fernandez et al. 2004 and references therein). This signal propagates into the stratosphere with a time delay associated with tropical mean upwelling. Scaife et al. (2003) showed in a general circulation model that there was an increase in water vapor entering the stratosphere during El Niño events. There is no clear evidence of a similar decrease in water vapor transport across the tropical tropopause during La Niña events. Hence ENSO is an important process determining lower stratospheric water vapor, although not as significant as QBO and planetary waves.

To realistically simulate the distribution and transport of lower stratospheric water vapor in a model, dynamical processes such as ENSO, QBO, and planetary wave breaking must be represented.

\subsection{Lower Stratospheric Water Vapor and Chemistry}

Chemistry is an important factor in the determination of the stratospheric water vapor field. Water vapor is produced in situ in the stratosphere by methane oxidation. The main oxidation of methane $\left(\mathrm{CH}_{4}\right)$ is by the hydroxyl radical $(\mathrm{OH})$, leading to water vapor through reaction 1:

$$
\mathrm{CH}_{4}+\mathrm{OH} \rightarrow \mathrm{CH}_{3}+\mathrm{H}_{2} \mathrm{O} \text {. }
$$

In this paper we have concentrated on the transport, hence the methane oxidation is not taken into consideration.

\subsection{Lower Stratospheric Water Vapor and Clouds}

In a typical lower stratosphere longitude-latitude water vapor field, we find the minimum 
water vapor in the tropical stratosphere and in the Antarctic winter stratosphere. In the tropical stratosphere, we expect the water vapor values to be low due to the very cold temperatures; however, the tropics are a region with very strong convection causing cumulus clouds to penetrate into the stratosphere. The temperature gradient and water vapor cause ice formation in the anvils of the convective towers. By gravity, the largest ice crystals fall out of the stratosphere causing dehydration of the lower tropical stratosphere.

When temperatures get extremely low like in the polar regions at winter Polar Stratospheric Clouds (PSCs) form. This occurs predominantly in the Antarctic polar vortex, although observed in the Arctic polar vortex with an increasing frequency (Rex et al. 2004). When PSCs form, water vapor is lost from the lower stratosphere by gravitational processes. This leads to dehydration. Without dehydration the polar vortex would be more humid than the surrounding air due to the vortex descent of air from higher altitudes containing more water vapor.

\section{MODEL DESCRIPTION}

The Community Atmosphere Model 3 (CAM3) is the fifth generation of the NCAR general circulation models. The model is integrated together with a land model and a thermodynamical sea-ice model. The ocean for the simulations considered in this paper is represented by observed sea surface temperatures from AMIP II (Taylor et al. 2001). The model has 26 layers in the vertical from the ground to $3 \mathrm{hPa}$ with 18 model layers in the troposphere and 8 layers in the stratosphere. The horizontal resolution is $2^{\circ} \times 2.5^{\circ}$. We use a finite volume dynamical representation following Lin and Rood (1996) and Lin (2004). The physical parameterizations are completely separated from the dynamical core. The model includes state of the art representations of convection, cloud and precipitation processes, radiative processes, vertical diffusion and atmospheric aerosols. A detailed description of the model is given by Collins et al. (2004).

\section{OBSERVATIONS AND REANALYSIS}

A severe problem in UTLS water vapor studies is the lack of observational data in this region. Ground based measurements often have the upper boundary in the tropopause region, while satellite data often have the tropopause region as the lower boundary. Therefore, many observations suffer from very large uncertainties. There are in situ measurements from aircraft campaigns available, but they are often both spatially and temporally limited. Reanalyzed datasets are convenient to use. However, they are strongly influenced by the reanalyses model, and cannot be considered as real observational data. In this paper, we use data from the Halogen Occultation Experiment (HALOE) onboard the Upper Atmosphere Research Satellite (UARS) (Russell et al. 1993) to validate water vapor in addition to ERA-40 reanalysis data from ECMWF (Kaallberg et al. 2004).

The HALOE instrument provides high-quality vertical profiles of water vapor, derived from solar occultation experiments. The vertical resolution of the version used here is $\sim 1.3 \mathrm{~km}$. HALOE measurements extend down to the approximate local tropopause level, below which cloud effects contaminate a significant fraction of the retrievals. HALOE is validated against other 
stratospheric water vapor measurements in the Stratospheric Processes and Their Role in Climate (SPARC) water vapor assessment study (WMO 2000). The HALOE instrument has been widely used for water vapor studies such as in the works of: Mote et al. (1996); Rosenlof et al. (1997); Considine et al. (2001); Randel et al. (2001); Geller et al. (2002); and Gettelman et al. (2002). We obtained the data from the SPARC Reference Climatology Project (randel@ucar. edu). HALOE water vapor measurements from 1991 - 2000 are averaged following the method of Randel et al. (1998), making use of the Microwave Limb Sounder (MLS) data also from UARS to fill in where HALOE lacks data.

The ERA-40 global reanalysis from ECMWF provides gridded data for the period 1957 2002. ERA-40 includes data from ground to $1 \mathrm{hPa}$ based on the use of variational data assimilation techniques. ERA-40 directly assimilates TOVS and ATOVS radiances, as opposed to retrieved temperature profiles. Detailed documentation is found in Kaallberg et al. (2004) and at the ECMWF web cite (http://www.ecmwf.int).

\section{RESULTS}

CAM3.0, forced by observed sea surface temperatures, was used to simulate the period January 1991 - December 2000. Ten-year means were analyzed focusing on seasonal variability in the lower stratospheric water vapor. Model results are compared to HALOE satellite data and ERA-40 reanalyses for the same period.

\subsection{Temperatures}

One of the main controlling factors for the amount of water vapor entering the stratosphere is temperature. The temperature at the tropical tropopause, the cold point, is shown to be crucial for the troposphere to stratosphere transport of water vapor as air is freeze dried when crossing this very cold region (Zhou et al. 2001; Geller et al. 2002; Randel et al. 2004b). Temperatures in the Southern Hemisphere (SH) polar winter are important for water vapor sedimentation through polar stratospheric cloud processes. Temperature gradients in the stratosphere influence the wind fields and are thus partly responsible for water vapor transport and distribution within the lower stratosphere. Figure 1 shows mean temperature profiles in different zonal mean latitude bands. The model results are shown in red and ERA-40 reanalyse temperatures in black. Solid lines denote January and dashed lines July. The temperature data are zonally averaged over different latitudinal bands as illustrated in Table 1 . This gives mean vertical profiles of water vapor in the UTLS region for pressure levels 300 to $50 \mathrm{hPa}$.

In the SH extratropics (BOX 1), we find significantly lower temperatures in July than in January due to the polar jet acting as a transport barrier. It isolates the polar vortex and allows extremely low temperatures to develop during the polar night. This seasonal variation, seen in the ERA-40 data, is well captured in the model. However, the model underestimates the temperatures compared to ERA-40 in this region in both seasons for altitudes below $80 \mathrm{hPa}$. At SH mid-latitudes (BOX 2) the model underestimates the temperatures between $300-150 \mathrm{hPa}$, while it gives a warm bias at levels $100-50 \mathrm{hPa}$, most pronounced in July where we find 5 - $6 \mathrm{~K}$ 


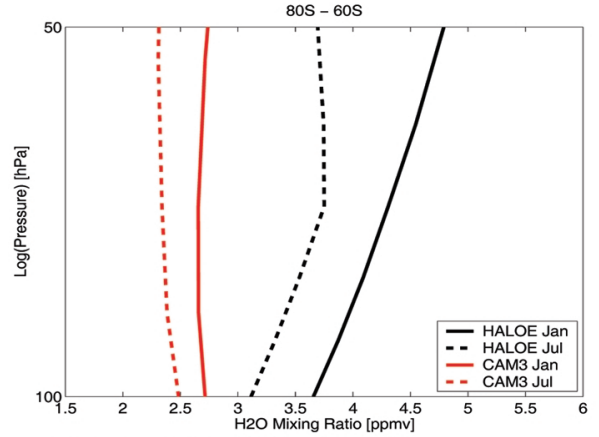

a) T zonal $80 \mathrm{~S}-60 \mathrm{~S}$ mean [K]

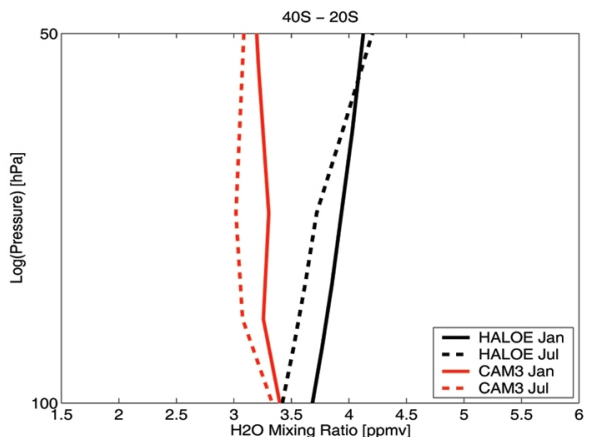

c) T zonal 40S-20S mean [K]

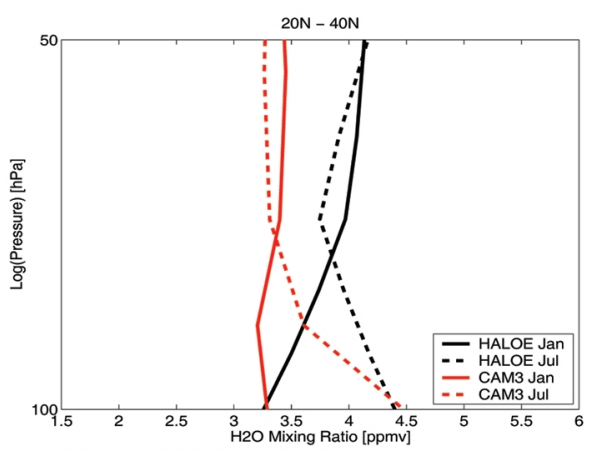

e) T zonal $20 \mathrm{~N}-40 \mathrm{~N}$ mean [K]

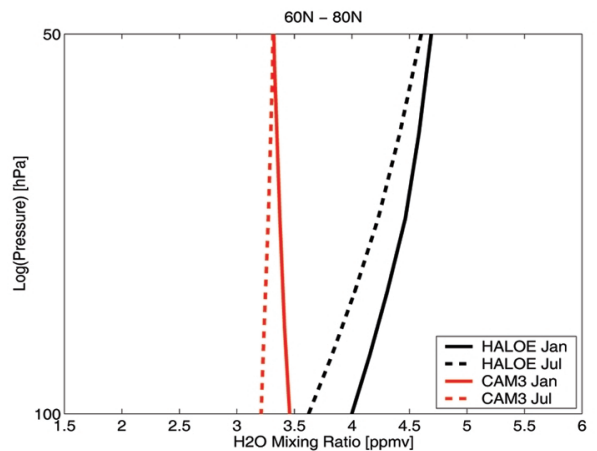

g) $\mathrm{T}$ zonal $60 \mathrm{~N}-80 \mathrm{~N}$ mean $[\mathrm{K}]$

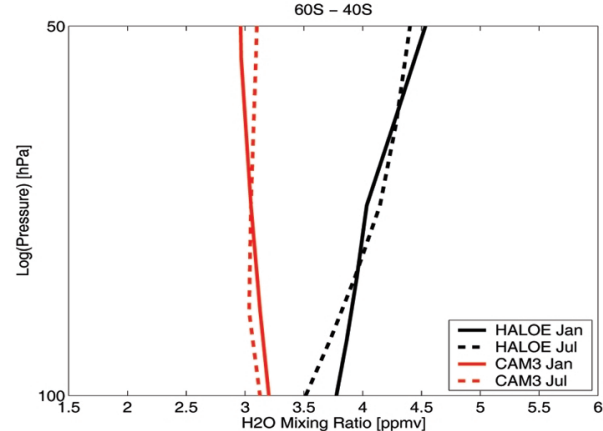

b) $\mathrm{T}$ zonal $60 \mathrm{~S}-40 \mathrm{~S}$ mean $[\mathrm{K}]$

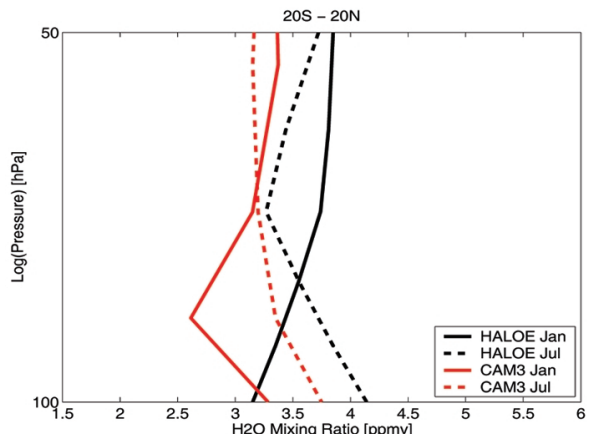

d) T zonal $20 \mathrm{~S}-20 \mathrm{~N}$ mean $[\mathrm{K}]$

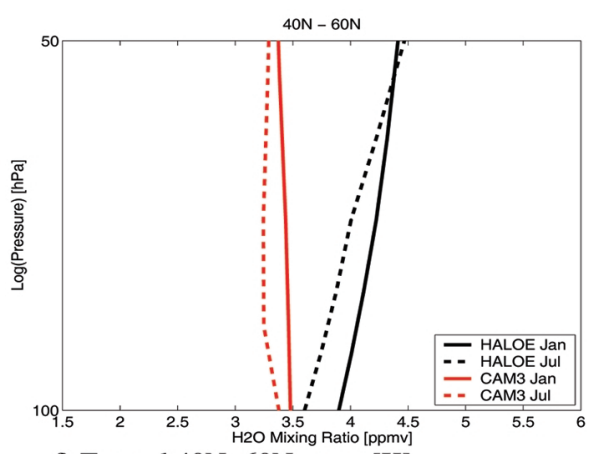

f) $\mathrm{T}$ zonal $40 \mathrm{~N}-60 \mathrm{~N}$ mean $[\mathrm{K}]$

Fig. 1. Temperature mean vertical profiles calculated as zonal means averaged over different latitude bands. January and July data are plotted together to illustrate seasonal variability. Solid lines denote January and dashed lines denote July. Red shows CAM3.0 results and black shows ERA-40 data. Temperature vs. $\log$ (Pressure) plots. 
Table 1. Zonal mean latitude bands for UTLS temperature analysis.

\begin{tabular}{lccc}
\hline & Longitude average & Latitude average & Pressure [hPa] \\
\hline BOX 1 & $0-360$ & $80 \mathrm{~S}-60 \mathrm{~S}$ & $300-50$ \\
BOX 2 & $0-360$ & $60 \mathrm{~S}-40 \mathrm{~S}$ & $300-50$ \\
BOX 3 & $0-360$ & $40 \mathrm{~S}-20 \mathrm{~S}$ & $300-50$ \\
BOX 4 & $0-360$ & $20 \mathrm{~S}-20 \mathrm{~N}$ & $300-50$ \\
BOX 5 & $0-360$ & $20 \mathrm{~N}-40 \mathrm{~N}$ & $300-50$ \\
BOX 6 & $0-360$ & $40 \mathrm{~N}-60 \mathrm{~N}$ & $300-50$ \\
BOX 7 & $0-360$ & $60 \mathrm{~N}-80 \mathrm{~N}$ & $300-50$ \\
\hline
\end{tabular}

deviation from ERA-40. In SH subtropics (BOX 3) there are remarkably good agreement between the model and ERA-40. This is also the case in the tropics (BOX 4), except at the tropical tropopause level, (the cold point). At the tropical tropopause the model has a cold bias of 2 - $3 \mathrm{~K}$ for both seasons; location of the cold point is slightly too high compared to ERA-40. In the Northern Hemisphere (NH) subtropics (BOX 5) and mid-latitudes (BOX 6), we find good agreements between the model and ERA-40. However, the temperature minimum at the tropopause is slightly cold biased in July in both boxes. In NH extratropics (BOX 7), we also underestimate the lowest temperatures. Apart from this the model results are in good agreement with ERA-40. Overall the location of the tropopause is realistically simulated in the model, except for some minor deviations in the tropics. This is a major improvement in the model, since previous versions of the NCAR general circulation models have struggled with large cold biases at the tropopause level as well as the location of the tropopause, especially in the tropics.

\subsection{Water Vapor Distribution in the Upper Troposphere}

In addition to good representation of temperature and transport, there must be a realistic amount of upper tropospheric water vapor available for transport. This has been a problem in earlier generations of the NCAR general circulation models, where the amount of water vapor in the uppermost troposphere has been significantly underestimated (Collins et al. 2005). This problem has been improved in the CAM3.0 model. Comparisons between ERA-40 reanalyses and CAM3.0 upper stratospheric water vapor are shown in Fig. 2. We find good agreement between ERA-40 and the model. Looking at the annual global mean water vapor mixing ratio 
at the $200 \mathrm{hPa}$ surface we find CAM3.0 to have a value of $24.6 \mathrm{ppmv}$ compared to $23.9 \mathrm{ppmv}$ in ERA-40. The general decrease of water vapor from equator to the poles is a reflection of the global distribution of temperature. As expected, amounts of water vapor are greatest over warm, equatorial regions and decrease more or less continuously with increasing latitude down to very low values over the cold polar regions. There are exceptions in the major desert regions, where the surface air is very dry despite its high temperature. The most humid region is in the western equatorial Pacific, above the so-called "oceanic warm pool", where the highest sea surface temperatures are found. The model captures these features well, although very slightly overestimating the global annual mean.

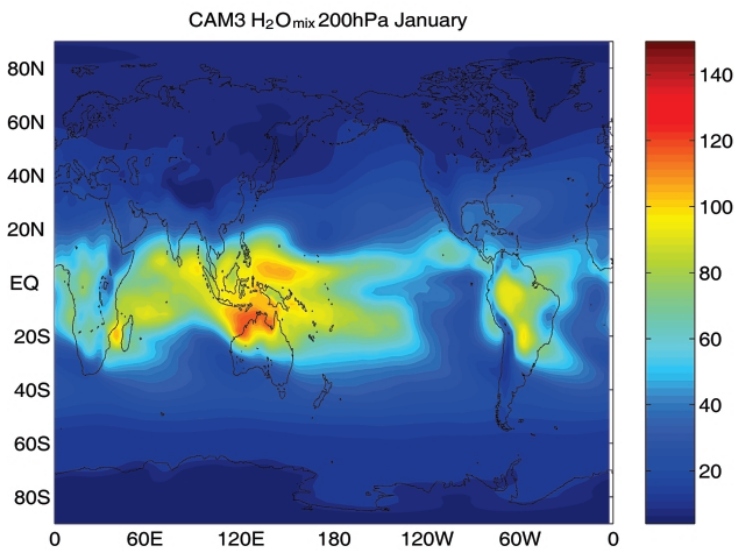

a) CAM $3.0200 \mathrm{hPa}$ January $\mathrm{H}_{2} \mathrm{O}_{\text {mix }}$ [ppmv]

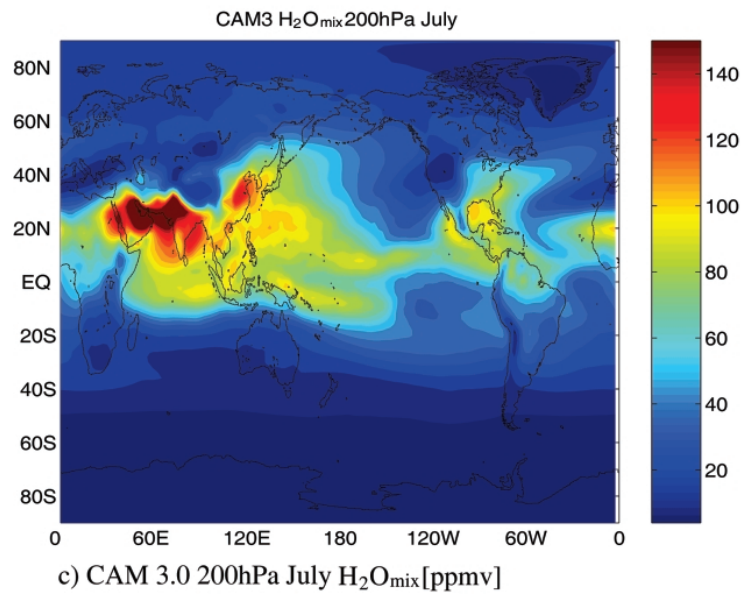

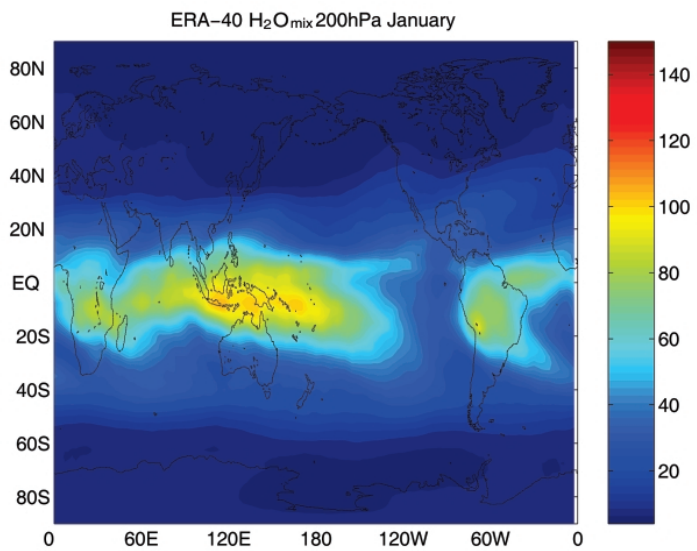

b) ERA-40 200hPa January $\mathrm{H}_{2} \mathrm{O}_{\text {mix }}$ [ppmv]

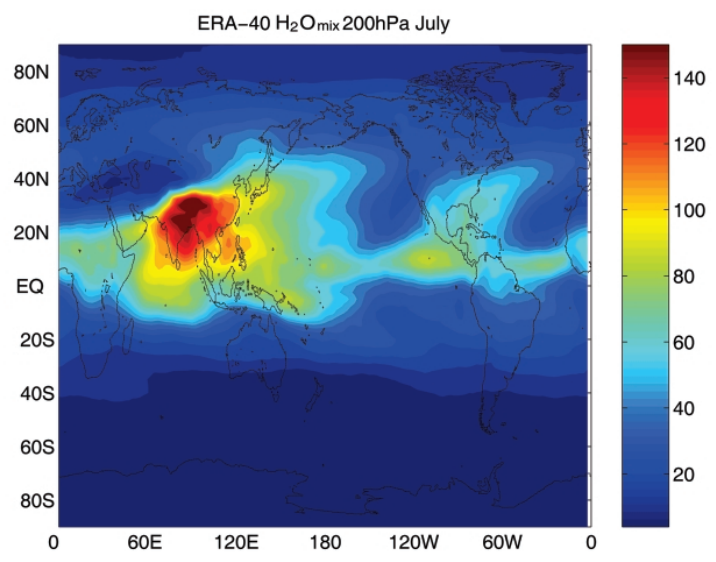

d) ERA-40 200hPa July $\mathrm{H}_{2} \mathrm{O}_{\text {mix }}$ [ppmv]

Fig. 2. $\mathrm{H}_{2} \mathrm{O}_{\text {mix }}$ (ppmv) as a function of longitude and latitude at $200 \mathrm{hPa}$. The model results from CAM3.0 for January and July are shown to the left and ERA-40 reanalyses are shown to the right. 


\subsection{Lower Stratospheric Water Vapor and Zonal Winds}

Zonal means of water vapor mixing ratio, $\mathrm{H}_{2} \mathrm{O}_{\text {mix }}$, simulated by CAM3.0 for all months are shown in Fig. 3 for January to June and Fig. 4 for July to December. Each plot includes water $\mathrm{H}_{2} \mathrm{O}_{\text {mix }}$ given in volume mixing ratio (ppmv) together with zonal wind $\mathrm{U}$ given in $\left(\mathrm{m} \mathrm{s}^{-1}\right)$ for the pressure region 100 to $10 \mathrm{hPa}$ which corresponds to approximately 16 to $32 \mathrm{~km}$ altitudes. $\mathrm{H}_{2} \mathrm{O}_{\text {mix }}$ is shown in colors and $\mathrm{U}$ is shown as contours. Solid contours denote positive $U$ values meaning westerlies and dashed contours denote negative $U$ values meaning easterlies. Figures 5 and 6 show similar plots as Figs. 3 and 4 for $\mathrm{HALOE} \mathrm{H}_{2} \mathrm{O}_{\text {mix }}$ in colors together with ERA-40 U as contours. Typical of observed $\mathrm{H}_{2} \mathrm{O}_{\text {mix }}$ from HALOE for all months is the large upwards and polewards increase. This increase is due to methane oxidation, which is not included in the model simulation presented in this paper. The methane oxidation parameterization is switched off in this model simulation to separately study the role of transport in the lower stratospheric water vapor budget. The dark red colors in the HALOE $\mathrm{H}_{2} \mathrm{O}_{\text {mix }}$ data in Figs. 5 and 6 indicate areas where the water vapor field is dominated by methane oxidation. The areas where the model results and the observations are comparable, typically the tropopause region and the tropical pipe are dominated by transport. Water vapor mainly originates from the troposphere and enters the stratosphere predominantly through the tropical tropopause, thereafter it is transported upwards and polewards by the Brewer-Dobson circulation (Brewer 1949). The main source of water vapor in the stratosphere, in addition to transport from the troposphere, is methane oxidation (discussed in previous sections), with small contributions from aircraft emissions (Gulstad et al. 2005a). From the plots in Figs. 3 - 6 the surfaces of constant $\mathrm{H}_{2} \mathrm{O}_{\text {mix }}$ are displaced upwards in the tropics and downward at higher latitudes. This is a typical tracer distribution in the lower stratosphere illustrating that the mean meridional mass transport is upward in the tropics and downward in the extratropics. Additionally $\mathrm{H}_{2} \mathrm{O}_{\text {mix }}$ and other tracers are subject to a faster quasi horizontal transport and mixing by planetary waves.

Ascending air is adiabatically cooled to a minimum in temperature at the tropical tropopause, the cold point. The air is freeze dried giving a minimum in $\mathrm{H}_{2} \mathrm{O}_{\text {mix }}$ at and just above the cold point. As the tropical tropopause temperature and mass transport have a significant seasonal cycle (Holton et al. 1995; Rosenlof 1995; Wong and Wang 2000; Randel et al. 2004a) the tropical tropopause $\mathrm{H}_{2} \mathrm{O}_{\text {mix }}$ also experiences a considerable seasonal variation. This will be further discussed later in this paper. From the $\mathrm{H}_{2} \mathrm{O}_{\text {mix }}$ observations given in Figs. 5 and 6, we find that tropical tropopause water vapor starts to decrease in December with its lowest values occurring in January and February located slightly to the north of equator. We find the minimum tropical troposphere $\mathrm{H}_{2} \mathrm{O}_{\text {mix }}$ value from observations to be around $2.5 \mathrm{ppmv}$. The model captures the $\mathrm{H}_{2} \mathrm{O}_{\text {mix }}$ minimum in the tropical tropopause. However, this minimum develops in November, one month earlier than in the observations. The model has slightly lower minimum values of $\mathrm{H}_{2} \mathrm{O}_{\text {mix }}$ than observations. This can be explained by the temperature bias at the models cold point. Furthermore, the driest point in the model seems to be located at a higher altitude than in the observations. Similarly, the model is unable to reproduce the northward displacement of the driest point, but produces a dry region which is much more displaced towards the Equator. The meridional scale of the tropical tropopause dry point expands between January and April in the model as well as in the observations. The minimum in $\mathrm{H}_{2} \mathrm{O}_{\text {mix }}$ seems to be transported 
Line Gulstad \& Ivar S. A. Isaksen
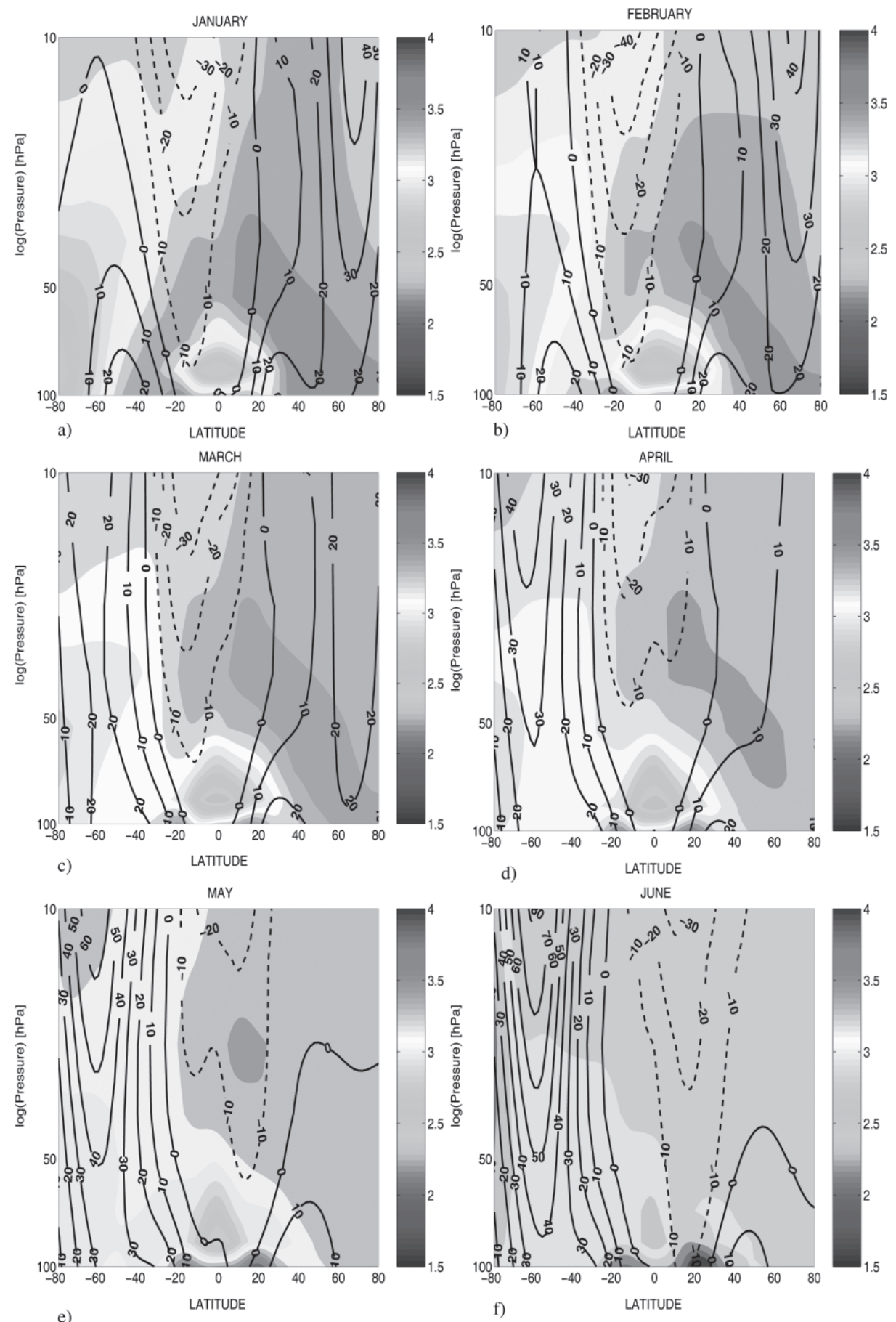

Fig. 3. $\mathrm{H}_{2} \mathrm{O}_{\text {mix }}$ (ppmv) in colors and zonal wind $\left(\mathrm{m} \mathrm{s}^{-1}\right)$ contours for January June. Latitude vs. log (Pressure) plots. 

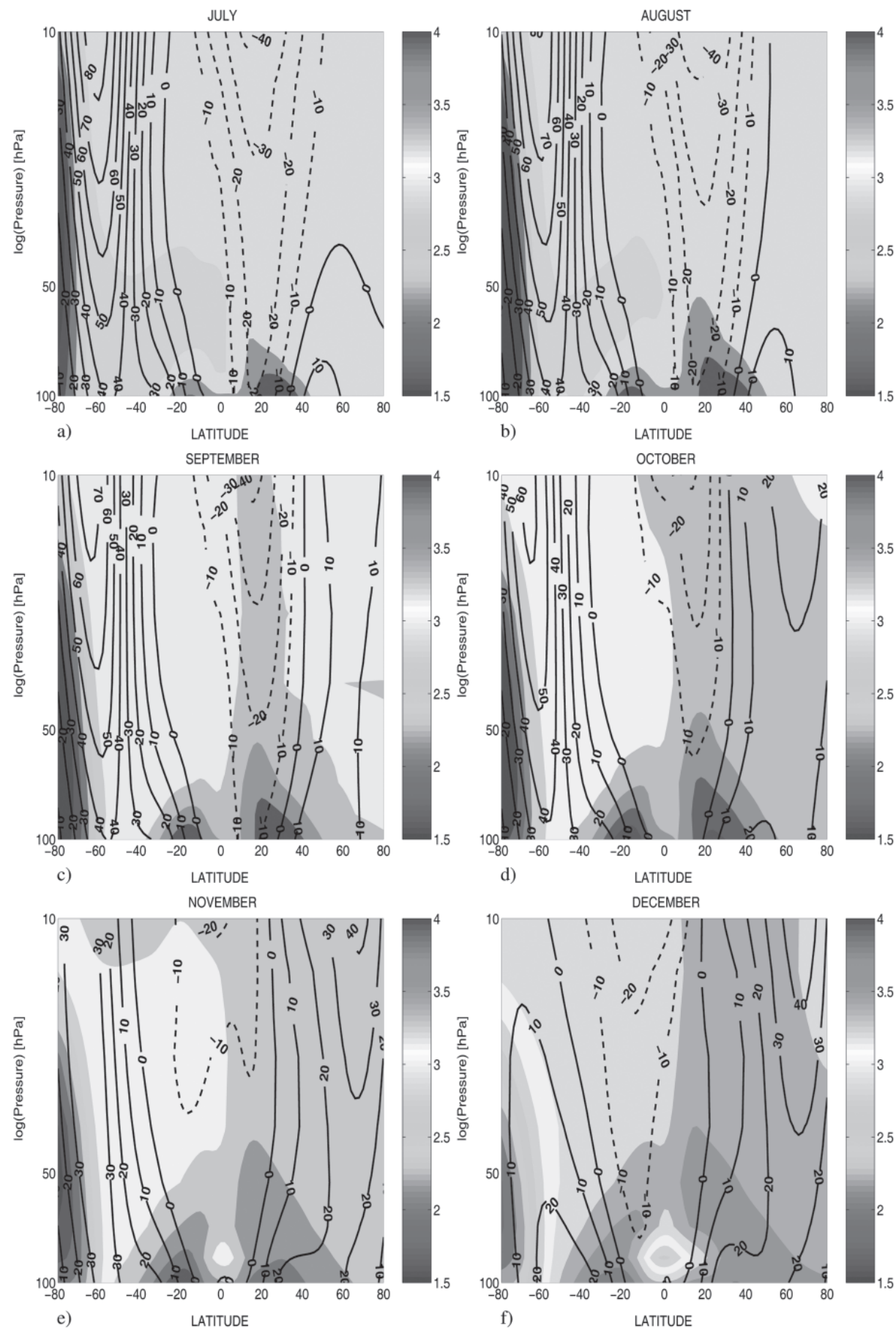

Fig. 4. $\mathrm{H}_{2} \mathrm{O}_{\text {mix }}$ (ppmv) in colors and zonal wind $\left(\mathrm{m} \mathrm{s}^{-1}\right)$ contours for July - December. Latitude vs. $\log$ (Pressure) plots. 

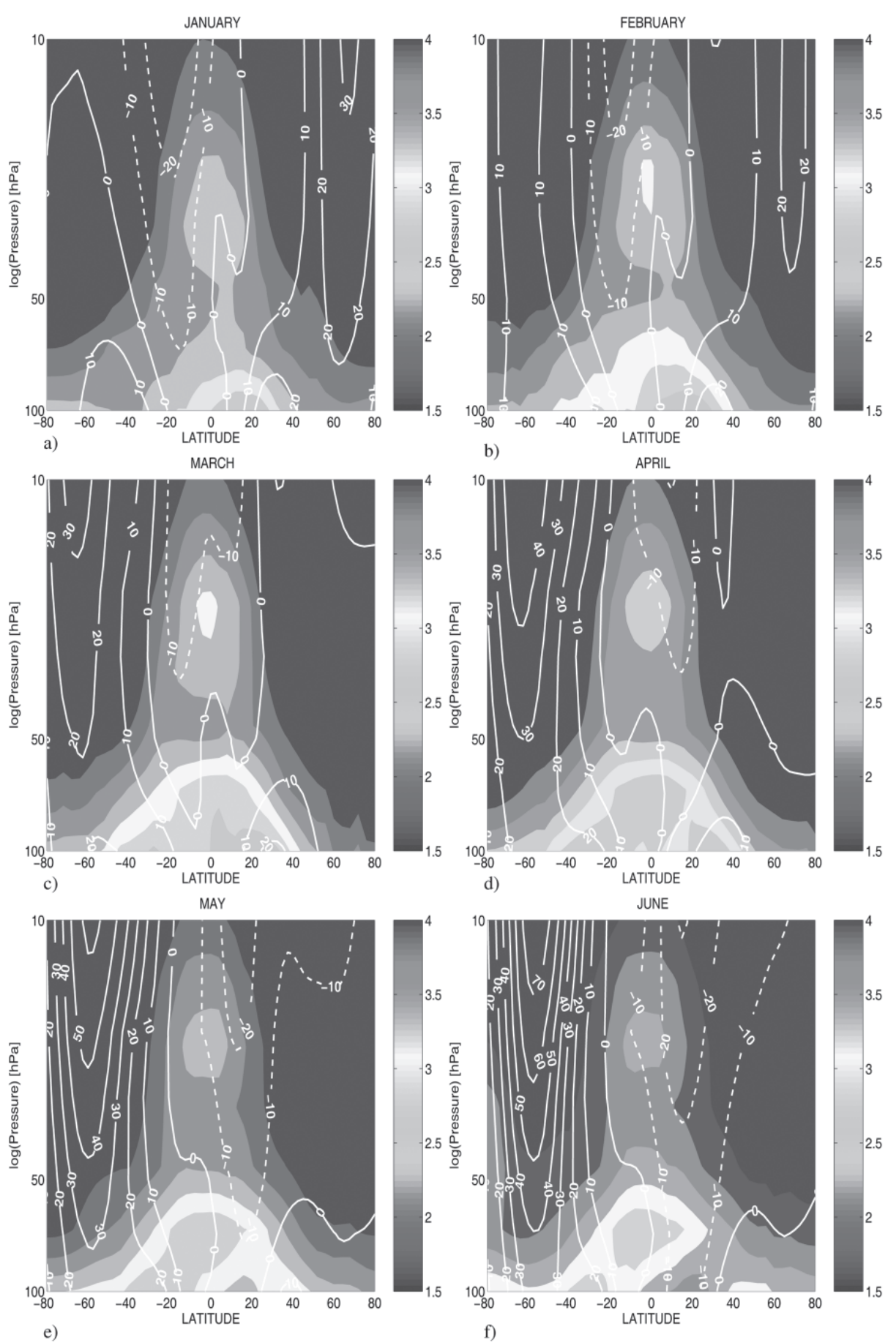

Fig. 5. $\mathrm{H}_{2} \mathrm{O}_{\text {mix }}$ (ppmv) in colors and zonal wind $\left(\mathrm{m} \mathrm{s}^{-1}\right)$ contours for January June. Latitude vs. log (Pressure) plots. 

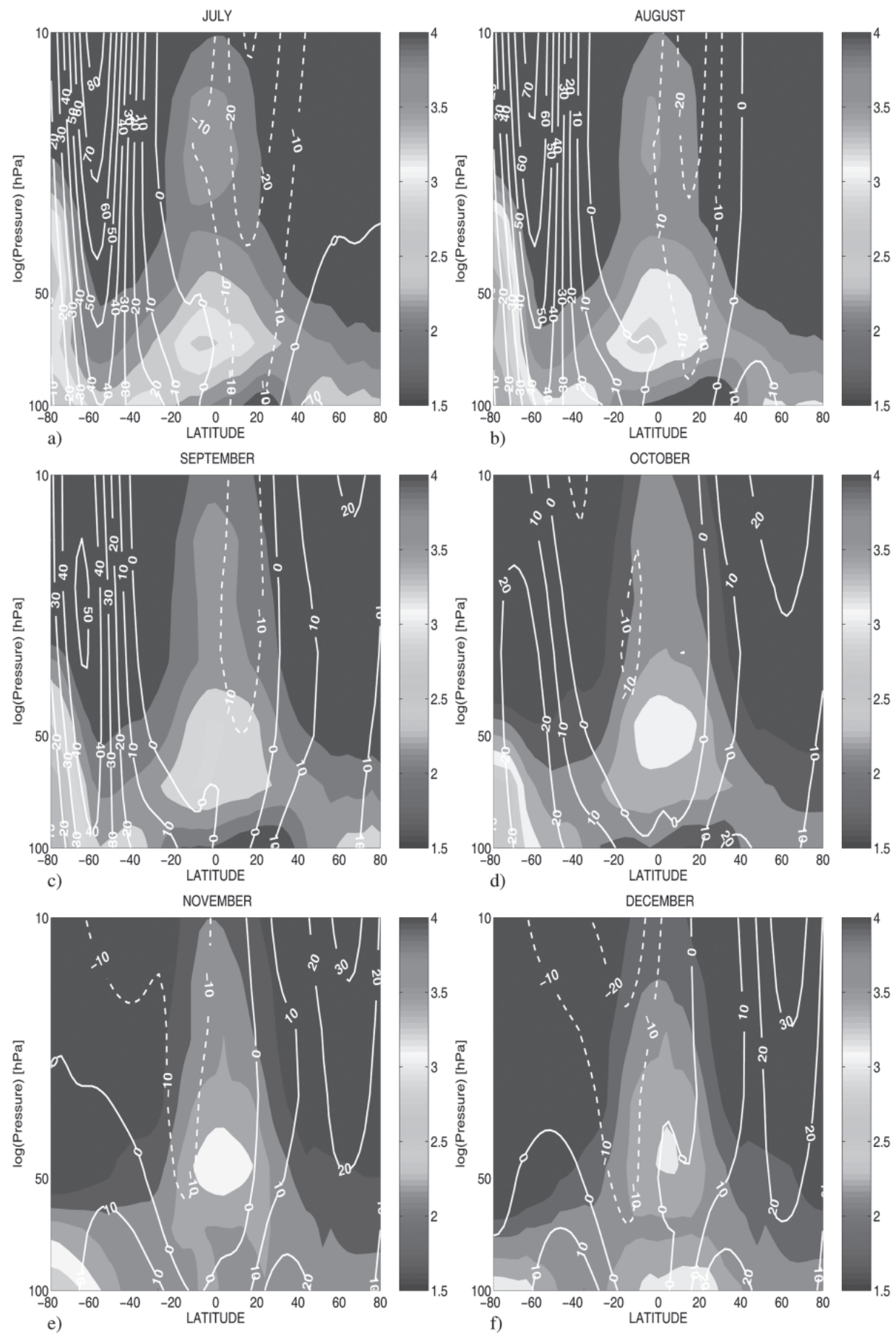

Fig. 6. $\mathrm{H}_{2} \mathrm{O}_{\text {mix }}$ (ppmv) in colors and zonal wind $\left(\mathrm{m} \mathrm{s}^{-1}\right)$ contours for July - December. Latitude vs. $\log$ (Pressure) plots. 
downwards and polewards suggesting quasi horizontal transport in the lowermost stratosphere as discussed in Randel et al. (2001). The gradients above $50 \mathrm{hPa}$ indicate a much more horizontally isolated tropical stratosphere at these levels. During most months a second minimum in $\mathrm{H}_{2} \mathrm{O}_{\text {mix }}$ is observed at higher altitudes which correspond to the upwards propagating annual cycle. This means that the air keeps its water vapor value from the last season as it propagates upwards and polewards. This corresponds to the so called Tape Recorder Signal (Mote et al. 1996) and will be further discussed.

In June, two typical features in the lower stratospheric water vapor field occur. As indicated by the gradient in the zonal wind $U$ the southern polar vortex starts to form in March in the observations and in the model in April, one month delayed. The polar night jet is strengthened as we move forward in time and reaches a maximum in July and August in the model as well as in the observations. The strong polar jet is acting as a transport barrier, isolating the air inside the polar vortex from the rest of the lower stratosphere. Due to the lack of insolation in the polar night, extremely low temperatures develop, as shown in Fig. 1. The low temperatures allow polar stratospheric clouds to form so that water vapor is sedimented out of the polar lower stratosphere. This phenomenon is indicated by very low $\mathrm{H}_{2} \mathrm{O}_{\text {mix }}$ values south of $60 \mathrm{~S}$ in the model, in agreement with the observations. However, in the model the $\mathrm{H}_{2} \mathrm{O}_{\text {mix }}$ inside the polar vortex is significantly low biased. This is mainly caused by the temperature bias in the model, but is also influenced by the low model top. The models upper boundary at $3 \mathrm{hPa}$ inhibits air from middle and upper stratosphere and mesosphere to descend inside the polar vortex bringing in air with higher $\mathrm{H}_{2} \mathrm{O}_{\text {mix }}$. The observations show that the $\mathrm{SH}$ polar vortex breaks up in October, while it persist to some extent throughout November in the model, leading to a significant underestimation of the $\mathrm{SH}$ extratropical $\mathrm{H}_{2} \mathrm{O}_{\text {mix }}$ throughout December. Another feature that occurs in June is a maximum in water vapor transported upward by cross isentropic transport in the region $10 \mathrm{~N}-40 \mathrm{~N}$. This is caused by the $\mathrm{NH}$ summer monsoon circulation. This circulation seems to be feeding the NH lower stratosphere with water vapor throughout the monsoon season. However the large water vapor mixing ratios in this region persist into October in the model, while this water vapor maximum is leveling off in September in the observational data. This can be explained by the summer period of the Asian monsoon persisting slightly too long in the model (Meehl et al. 2006).

The zonal wind has a significant seasonal variability, which is shown in contours in Figs. 3 and 4 for the model and Figs. 5 and 6 for the ERA-40 reanalysis. The largest seasonal variations are obviously found where we have the largest seasonal variations in the temperatures as previously discussed and shown in Fig. 1. The variability in the zonal wind during an annual cycle in the model corresponds fairly well with the ERA-40 zonal wind. The SH polar jet onset occurs in April in the model, which is one month delayed compared to ERA-40. This is also the case for the SH polar vortex break up. The Northern Hemisphere $(\mathrm{NH})$ polar jet is stronger in magnitude as well as zonality in the model compared to ERA-40. The NH polar vortex persists throughout March in the model while breaking up in February in ERA-40. This indicates that the model does not reproduce well variability due to wave activity and north/south motion of weather fronts that occur to a high extent during $\mathrm{NH}$ winter. The largest discrepancy between ERA-40 and model zonal winds occurs in the equatorial stratosphere where the model seems to significantly overestimate the easterly wind speeds during most of the year. This is due to 
the fact that the model does not reproduce the QBO. During the period over which our model and observations are averaged, 1991 - 2000, there have been four periods of alternating westerlies in the ERA-40 tropical stratosphere. The model maintains easterlies in the tropical stratosphere throughout this period. The speed of the easterlies in the model varies, however the winds never change to westerlies. This shortcoming influences the 10 year zonal mean wind shown in Figs. 5 and 6, and explains the deviations between model and ERA-40 zonal winds in the equatorial stratosphere. If only easterly periods of QBO from the ERA-40 data are considered in the average, the ERA-40 and CAM3.0 tropical zonal winds are comparable.

\subsection{Stratospheric Transport}

The UTLS region is dominated by extreme gradients in temperature and humidity. While water vapor in the upper troposphere is controlled by diabatic processes, it is controlled in the lower stratosphere by advection by the large scale Brewer-Dobson circulation. In the absence of sources and sinks, water vapor is a nearly conserved quantity in the LS, and thus a useful tracer for stratospheric transport. Tropical LS water vapor has a seasonal variation depending on the seasonality of the tropical tropopause as mentioned in the previous section. Water vapor values in the tropical lower stratosphere vary between a maximum of $4.5 \mathrm{ppmv}$ in northern hemispheric summer to a minimum of $2.5 \mathrm{ppmv}$ in Northern hemispheric winter. Due to the very slow mixing of air masses in this region the air continues to have low winter values and high summer values as it propagates slowly upwards with the Brewer-Dobson circulation. The air "remembers" its tropopause water vapor content like a tape recorder, which explains the name Stratospheric Tape Recorder Signal (Mote et al. 1996). From the HALOE instrument it is observed that this signal propagates from 16 to $32 \mathrm{~km}$ altitudes in around 18 months. As the signal moves upward, it is attenuated with an e-folding time of about 7 to 9 months between 16 and $21 \mathrm{~km}$ and about 15 to 18 months between 21 and $32 \mathrm{~km}$. The strong attenuation in the lowest part of the tropical lower stratosphere suggests transport from the tropics to higher latitudes (Randel et al. 2001). This is not taking place at slightly higher altitudes where we find the tropical stratosphere to be much more isolated. We have calculated the Tape Recorder Signal for the model, shown in Fig. 7a and compared this to the observed HALOE tape recorder, Fig. 7b. The signals are calculated as a zonal mean of the lower stratosphere, $100-10 \mathrm{hPa}$, averaged over the tropics $15 \mathrm{~S}-15 \mathrm{~N}$. The signal is shown as deviation from annual mean which gives negative values for low water vapor content in $\mathrm{NH}$ winter and positive values for $\mathrm{NH}$ summer. A time series of 12 months is shown for month 1 January to month 12 December. The time series is calculated from a climatological year based on a 1991 - 2000 average for the model as well as for the HALOE data. The HALOE tape recorder is calculated from a climatology based on data taken from the Upper Research Atmosphere Project (URAP) (Remedios 2001). From the comparison of the HALOE and model Tape Recorder Signal we find the model to have a realistic vertical propagation velocity and to be quantitatively comparable with HALOE water vapor values; however, the water vapor minimum is attenuated too quickly in the model. This indicates a too strong horizontal mixing in the $\mathrm{NH}$ winter. The altitudinal displacement of the tropical tropopause forces the maximum value to occur slightly too high, except for this the maximum value in the model seems to be realistic. The maximum in the upper part of the HALOE 


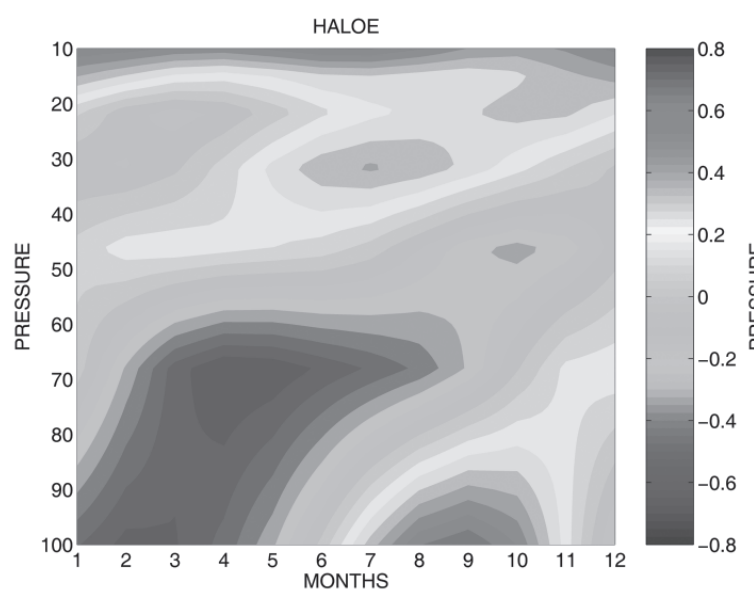

a) HALOE Tape Recorder signal

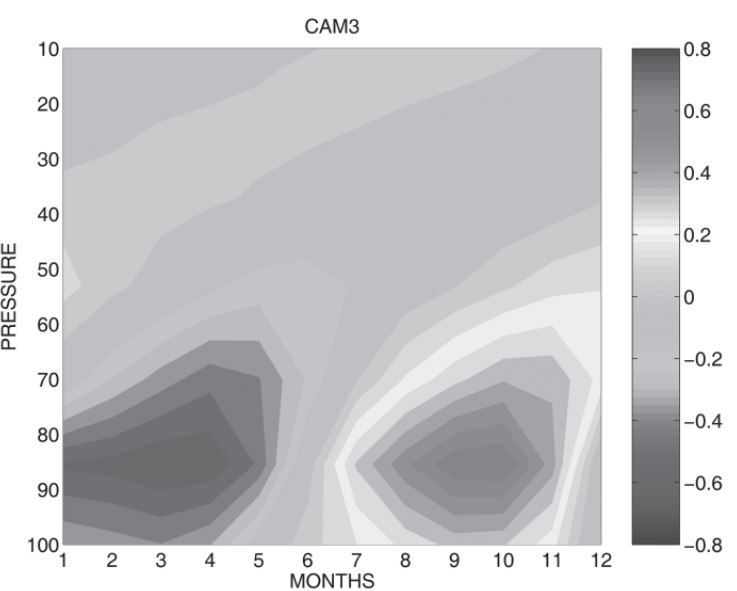

b) CAM3.0 Tape Recorder signal

Fig. 7. HALOE (a) and CAM3.0 (b) Tape Recorder Signals calculated for zonal and $15 \mathrm{~N}-15 \mathrm{~S}$ average of $\mathrm{H}_{2} \mathrm{O}_{\text {mix }}$ as a function of month and pressure. Values are shown as deviation, in (ppmv), from annual mean calculated from a climatological year based on 1991 - 2000.

tape recorder plot is due to methane oxidation and must be ignored in this comparison, since the contribution from methane is not considered in this model study. The meridional exchange of water vapor between the tropics and mid latitudes is shown in Fig. 8 for 100 and $70 \mathrm{hPa}$ pressure surfaces. At $100 \mathrm{hPa}$ we find a minimum in HALOE $\mathrm{H}_{2} \mathrm{O}_{\text {mix }}$ in February and March around EQ-20N. This minimum propagates to high latitudes during a period of 2 - 3 months. In the model, a corresponding minimum occurs also for the region EQ-20N but with a slightly earlier appearance than in HALOE. The model has a very realistic transport to NH high latitudes while the SH transport is more difficult to identify since the influence of the remaining dry biased polar vortex air disturbs the signal. The observational maximum in $\mathrm{H}_{2} \mathrm{O}_{\text {mix }}$ starts to develop in June between $20 \mathrm{~N}-40 \mathrm{~N}$, and expands to a region covering $20 \mathrm{~S}-40 \mathrm{~N}$ two months later. This maximum is a combination of two processes: the NH summer monsoon which is moistening the $\mathrm{NH}$ subtropics to mid-latitudes and the moistening of the $\mathrm{SH}$ subtropics due to the seasonal maximum in tropopause temperatures during $\mathrm{NH}$ summer. The maximum is transported to high latitudes in a period of 2 - 4 months. In the model, these two maxima are clearly separated by a local minimum in $\mathrm{H}_{2} \mathrm{O}_{\text {mix }}$ at the Equator. This is connected to the model having a tendency to produce a double intertropical convergence zone (ITCZ) (Hack et al. 2006). The transport time to higher altitudes in the model seems to be fairly realistic but the amount of water vapor transported from tropics to higher latitudes is underestimated. This indicates that the transport from the tropics to higher latitudes in the lowermost stratosphere is too week. At $68.1 \mathrm{hPa}$ for HALOE compared to $70 \mathrm{hPa}$ in the model we find an increase in $\mathrm{H}_{2} \mathrm{O}_{\text {mix }}$ in the HALOE data when moving polewards. This is due to methane oxidation and must not be taken into account 

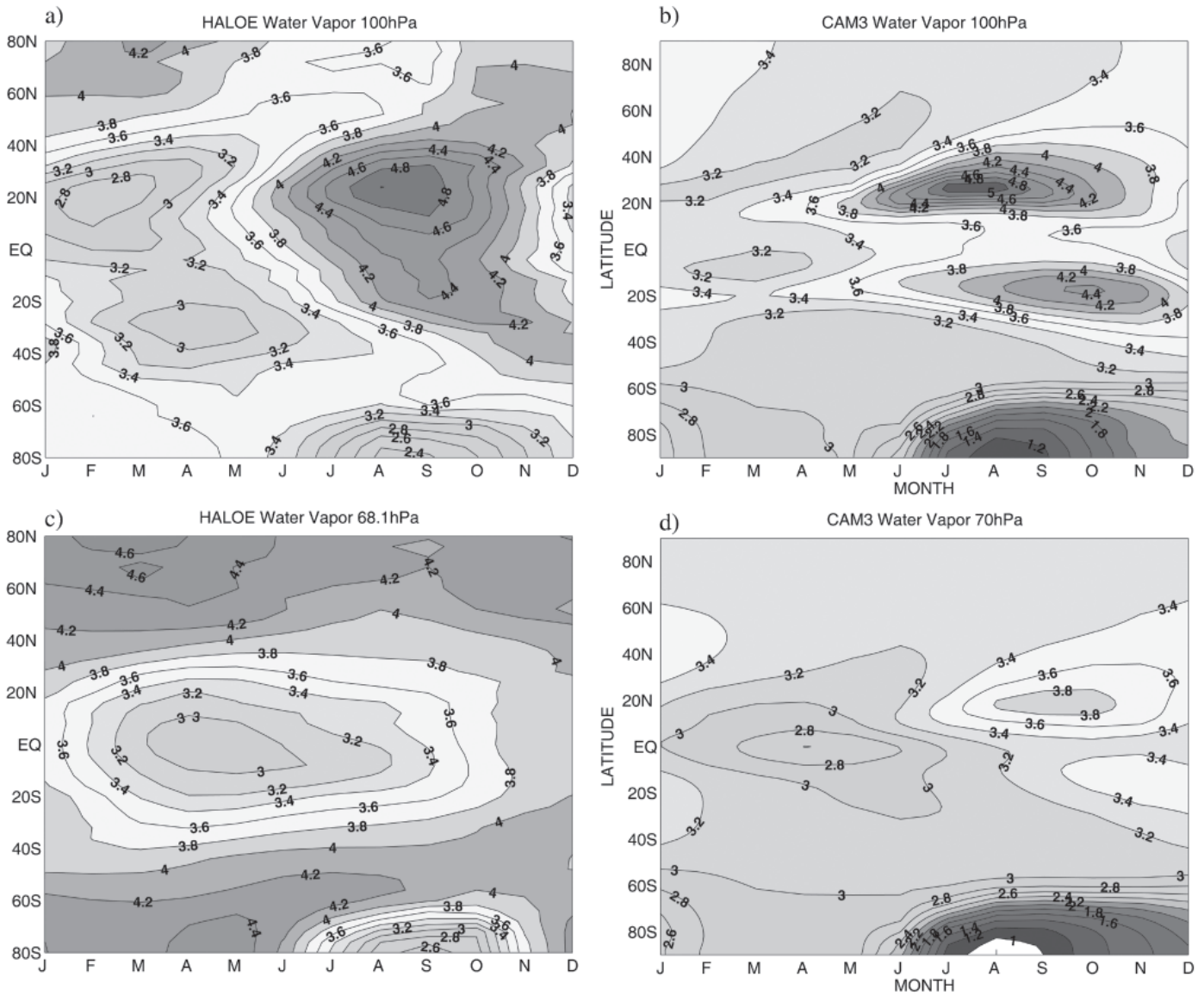

Fig. 8. HALOE (a) and CAM3.0 (b) zonal mean annual $\mathrm{H}_{2} \mathrm{O}_{\text {mix }}$ cycle for $100 \mathrm{hPa}$. HALOE (c) and CAM3.0 (d) zonal mean annual $\mathrm{H}_{2} \mathrm{O}_{\text {mix }}$ cycle for $68.1 \mathrm{hPa}$ for HALOE and $70 \mathrm{hPa}$ for the model. Data shown as a function of month and latitude. Values in (ppmv) calculated from a mean year based on 1991 -2000 .

in this comparison as previous mentioned. At this pressure level there is less meridional transport in the observations, which indicates that the tropical stratosphere is more isolated at higher altitudes as already indicated by the Tape Recorder analysis. The model has less horizontal transport at $70 \mathrm{hPa}$ than at $100 \mathrm{hPa}$ indicating an increasing isolation of the tropics with altitude. However, the model is not able to reproduce the same degree of horizontal isolation as we find in the observations. This is also indicated by the slightly too fast attenuation of the tape recorder signal. The temporal scale in Fig. 8 is approximately the same for HALOE and the model, which shows that the Brewer-Dobson circulation in the model is fairly realistic. This can be seen as the maximum and minimum in the tropical water vapor at the two pressure 
levels appear at the correct time compared to the observations. Hence the propagation time for the water vapor signal from 100 to $70 \mathrm{hPa}$ is realistic. From these plots it is clear that the dry bias in SH polar vortex has a significant influence on the total $\mathrm{SH}$ water vapor field throughout the year.

\section{DISCUSSION AND CONCLUSIONS}

The CAM3.0 model captures the seasonal variability relatively well with respect to UTLS temperature and water vapor. The zonal wind has a realistic seasonal cycle outside the tropics. In the tropical region, the lack of QBO in the model influences the zonal wind field. When the ERA-40 dataset is analyzed we find four westerly QBO periods for 1991 - 2000. In the model simulation we find easterlies throughout the same period. This leads to a considerably stronger easterly zonal wind in the model compared to ERA-40 when 1991 - 2000 averages are analyzed. If we consider ERA-40 easterly phases only, the model and ERA-40 become comparable. The UTLS temperature correlates well with ERA-40 temperatures. The tropopause cold biases from previous versions of the NCAR general circulation models are significantly reduced. However, we find regions where the cold bias is still considerable. Antarctic polar temperatures are underestimated with as much as $5 \mathrm{~K}$ in July and up to $10 \mathrm{~K}$ in January. This has a considerable effect on the water vapor field throughout the SH. The amount of water vapor in the upper troposphere corresponds with ERA-40 in distribution as well as global mean values. The major improvement in CAM3.0, compared to previous versions, is seen in the stratospheric transport. We find that the model exhibit a realistic Brewer-Dobson circulation with respect to vertical propagation velocity, as well as giving realistic location and timing of the water vapor minima and maxima. This is encouraging since the model's general circulation in the stratosphere has been a strong argument for not using the previous NCAR GCMs for stratospheric studies. It should be pointed out that model performance in the lower stratosphere is highly dependent on the dynamical core, as closely discussed in Gulstad (2005). We find a slightly too fast attenuation of the Tape Recorder Signal, which suggests a too strong quasi horizontal mixing in the model. This might be connected to the lack of QBO and also to the crude representation of planetary waves.

From this work we conclude that the UTLS water vapor in CAM3.0 is realistically re-produced, quantitatively as well as qualitatively, despite the fact that the top model layer is at $3.5 \mathrm{hPa}$ and that the model lacks a QBO signal. We find CAM3.0 suitable for the study of distribution and transport of UTLS water vapor and other tracers.

Acknowledgements We are grateful to Philip J. Rasch at the National Center for Atmospheric research (NCAR) for scientific discussions. We thank Karen Rosenlof at National Oceanic and Atmospheric Administration Aeronomy Laboratory (NOAA) for providing HALOE data and software. The work presented in this paper has been supported by the Norwegian Research Council through the project Tropospheric Chemistry and Climate (ChemClim). Furthermore, this work has received support from the Norwegian research council's program for supercomputing through a grant of computer time. 


\section{REFERENCES}

Baldwin, M., L. Gray, T. Dunkerton, K. Hamilton, P. Haynes, W. Randel, J. Holton, M. Alexander, I. Hirota, T. Horinouchiand, D. Jones, J. Kinnersleya, C. Marquardt, K. Sato, and M. Takahashi, 2001: The quasi-biennial oscillation. Rev. Geophys., 39, 179229.

Brewer, A. W., 1949: Evidence for a world circulation provided by the measurements of helium and water vapour distribution in the stratosphere. Q. J. R. Meteorol. Soc., 75, 351-363.

Clark, H., A. Billingham, R. Harwood, and H. Pumphrey, 2001: Water vapour in the tropical lower stratosphere during the driest phase of the atmospheric tape recorder. J. Geophys. Res., 106, 22695-22705.

Collins, W., P. Rash, B. Boville, J. Hack, J. McCaa, D. Williamson, J. Kiehl, and B. Briegleb, 2004: Description of the ncar community atmosphere model (CAM3.0). Ncar Technical Note, NCAR/TN-464+STR.

Collins, W., P. Rasch, B. Boville, J. Hack, J. McCaa, D. Williamson, B. Brieglieb, C. Bitz, S. J. Lin, and M. Zhang, 2005: The formulation and atmospheric simulation of the community atmosphere model version 3 (CAM3). J. Climate, 19, doi: 10.1175/JCLI3760.1.

Considine, D. B., J. E. Rosenfield, and E. L. Fleming, 2001: Interactive model study of the influence of the Mount Pinatubo aerosol stratospheric methane and water trends. $J$. Geophys. Res., 106, 27711-27ß727.

Dobson, G. M. B., 1956: Origin and distribution of polyatomic molecules in the atmosphere. Proc. Roy. Soc. London, A236, 187-193.

Fernandez, N., R. Garcia, R. Herrera, D. Puyol, L. Presa, E. Martin, and P. Rodriguez, 2004: Analysis of the ENSO signal in tropospheric and stratospheric temperatures observed by MSU. J. Climate, 17, 3934-3946.

Geller, M. A., X. Zhou, and M. Zhang, 2002: Simulations of the variability of stratospheric water vapor. J. Atmos. Sci., 59, 1076-1085.

Gettelman, A., W. J. Randel, F. Wu, and S. T. Massie, 2002: Transport of water in the tropical tropopause. Geophys. Res. Lett., 29, 1-4.

Gulstad, L., 2005: Modelling UTLS Water Vapor: Transport/chemistry interactions. Series of dissertations submitted to the Faculty of Mathematics and Natural Sciences, University of Oslo, No.455, 2005.

Gulstad, L., G. Pitari, V. Grewe, O. Dessens, E. Mancini, A. Stencke, C. Marizy, H. Rogers, J. Pyle, M. Gauss, O. A. Soevde, I. S. A. Isaksen, D. Caro, R. Ramaroson, 2005a: Model intercomparison of future supersonic aircraft impact on stratospheric water vapor. In preparation for Journal of Climate.

Hack, J. J., J. M. Caron, S. G. Yeager, K. W. Oleson, M. M. Holland, J. E. Truesdale, and P. J. Rasch, 2006: Simulation of the global hydrological cycle in the CCSM Community Atmosphere Model Version 3 (CAM3): Mean features. J. Climate, 19, 2199-2221.

Holton, J., P. Haynes, M. McIntyre, A. Douglass, R. Rood, and L. Pfister, 1995: Stratospheretroposphere exchange. Rev. Geophys., 33, 403-439.

IPCC, 2001: Intergovernmental Panel on Climate Change's Synthesis Report, Climate Change 
2001, 5 (web versions of 2001 IPCC reports).

Jackson, D., S. Driscoll1, E. Highwood, J. Harries, and J. R. III, 1996: Lower stratospheric water vapor at low latitudes as observed by haloe. Proceedings of the 1st General Assembly of the WCRP Project 'Stratospheric Processes and their Role in Climate' (SPARC), 1.

Kaallberg, P., A. Simmons, S. Uppala, and M. Fuentes, 2004: The ERA-40 archive. ERA-40 Project Report Series, 17, ECMWF.

Lin, S. J., 2004: A vertically lagrangian finite-volum edynamical core for global models. Mon. Weather Rev., 132, 2293-2307.

Lin, S. J., and R. Rood, 1996: Multidimensional flux-form semi-lagrangian transport schemes. Mon. Weather Rev., 124, 2046-2070.

Meehl, G. A., J. M. Arblaster, D. M. Lawrence, A. Seth, E. K. Schneider, B. P. Kirtman, and D. Min, 2006: Monsoon regimes in the CCSM3. J. Climate, 19, 2482-2495.

Mote, P., K. Rosenlof, M. McIntyre, E. Carr, J. Gille, J. Holton, J. Kinnersley, H. Pumphrey, J. Russell, and J. Waters, 1996: An atmospheric tape recorder: The imprint of tropical tropopause temperatures on stratospheric water vapor. J. Geophys. Res., 101, 39894006.

O'Sullivan, D., and T. Dunkerton, 1997: The influence of the quasi-biennial oscillation on global constituent distributions. J. Geophys. Res., 102, 21731-21743.

Randel, W., F. Wu, J. R. III, A. Roche, and J. Waters, 1998: Seasonal cycles and QBO variations in stratospheric $\mathrm{CH}_{4}$ and $\mathrm{H}_{2} \mathrm{O}$ observed in UARS HALOE data. J. Atmos. Sci., 55, 163-185.

Randel, W., F. Wu, A. Gettelman, J. R. III, J. Zawodny, and S. Oltmans, 2001: Seasonal variation of water vapor in the lower stratosphere observed in halogen occultation experiment data. J. Geophys. Res., 106, 14313-14325.

Randel, W., F. Wu, S. Oltmans, K. Rosenlof, and G. Nedoluha, 2004a: Interannual changes of stratospheric water vapor and correlations with tropical tropopause temperatures. $J$. Atmos. Sci., 61, 2133-2148.

Randel, W. P. U., E. Fleming, M. Geller, M. Gelman, K. Hamilton, D. Karoly, D. Ortland, S. Pawson, R. Swinbank, F. Wu, M. Baldwin, M. L. Chanin, P. Keckhut, K. Labitzke, E. Remsberg, A. Simmons, and D. Wu, 2004b: The sparc intercomparison of middleatmosphere climatologies. J. Climate, 17, 986-1003.

Remedios, J., 2001: Uars reference atmosphere project. http://code916.gsfc.nasa.gov/Public/ Analysis/UARS/urap/home.html.

Rex, M., R. Salawitch, P. von der Gathen, H. N. R, P, M. Chipperfield, and B. Naujokat, 2004: Arctic ozone loss and climate change. Geophys. Res. Lett., 31, L04116, doi: 10. 1029/2003GL018844.

Rosenlof, K. H., 1995: Seasonal ciycle of the residual mean meredional circulation in the stratosphere. J. Geophys. Res., 100, 5173-5191.

Rosenlof, K. H., A. F. Tuck, K. K. Kelly, J. M. R. III, and M. P. McCormick, 1997: Hemispheric asymmetries in water vapor and inferences about transport in the lower stratosphere. J. Geophys. Res., 102, 13213-13234.

Russell, J. M. I., L. L. Gordley, J. H. Park, S. R. Drayson, D. H. Hesketh, R. J. Cicerone, A. F. 
Tuck, J. E. Frederick, J. E. Harries, and P. J. Crutzen, 1993: The halogen occultation experiment. J. Geophys. Res., 98, 10777-10797.

Scaife, A., N. Butchart, D. Jackson, and R. Swinbank, 2003: Can changes in ENSO activity help to explain increasing stratospheric water vapor? Geophys. Res. Lett., 30, 1880, doi: 10.1029/2003GL017591.

Taylor, K., D. Williamson, and F. Zwiers, 2001: Amip ii sea surface temperature and sea ice concentration boundary conditions. Program for Climate Model Diagnosis and Intercomparison, 23 June 1997 (revised 6 April 2001).

Walker, G., 1924: Correlation in seasonal variation of weather, ix: A further study of world weather. Mem. Indian Meteorol. Dept., 24, 275-332.

WMO, 2000: Stratospheric processes and their role in climate (sparc) asassment of upper tropospheric and stratospheric water vapour. SPARC, Rep.2 WCRP-113 WMO/TD1043.

Wong, S., and W. C. Wang, 2000: Interhemispheric asymmetry in the variation of the zonal mean tropopause. J. Geophys. Res., 105, 26645-26659.

Zhou, X., M. A. Geller, and M. H. Zhang, 2001: The cooling trend of the tropical cold point tropopause temperatures and its implications. J. Geophys. Res., 106, 1511-1522.

Gulstad, L., and I. S. A. Isaksen, 2007: Modeling water vapor in the upper troposphere and lower stratosphere. Terr. Atmos. Ocean. Sci., 18, 415-436, doi: 10.3319/TAO.2007.18. 3.415(EA). 